\title{
Development of a Canadian Core Clinical Dataset to Support High-quality Care for Canadian Patients with Rheumatoid Arthritis
}

\author{
Claire E.H. Barber, Dianne P. Mosher, Vandana Ahluwalia, Michel Zummer, Deborah A. \\ Marshall, Denis Choquette, Diane Lacaille, Claire Bombardier, Anne Lyddiatt, Vinod Chandran, \\ Dmitry Khodyakov, Emily Dao, and Cheryl Barnabe, for the RACCD Working Group
}

\begin{abstract}
Objective. To develop a Canadian Rheumatoid Arthritis Core Clinical Dataset (CAN-RACCD) to standardize documentation encouraging high-quality care.

Methods. A set of candidate elements was drafted through meetings with 27 rheumatologists, researchers, and patients, and supplemented with focused literature reviews. A 3-round online-modified Delphi consensus process was held with rheumatologists $(n=26)$, allied health professionals $(n=7)$, and patients $(n=4)$; for the remainder there was no demographic information. Participants rated both the importance and feasibility of documenting candidate elements on a Likert scale of 1-9, contributed to an online moderated discussion, and re-rated the elements for inclusion in the CAN-RACCD. Elements were included in the final set if importance and feasibility ratings had a median score of $\geq$ 6.5 and there was no disagreement among participants.

Results. Fifty-five individual elements in 10 subgroups were proposed to the Delphi participants: measures of RA disease activity; dates to calculate waiting times, disease duration, and disease-modifying antirheumatic drug start; comorbidities; smoking status; patient-reported pain and fatigue; physical function; laboratory and radiographic investigations; medications; clinical characteristics; and vaccines. All groups were included in the final set, with the exception of vaccination status. Additionally, 3 individual elements from the smoking subgroup were eliminated with a recommendation to record smoking status as never/ever/current, and 2 elements relating to coping and effect of fatigue were eliminated due to low feasibility and importance ratings.

Conclusion. The CAN-RACCD stands as a national recommendation on which data elements should be routinely collected in clinical practice to monitor and support high-quality RA care. (First Release October 1 2017; J Rheumatol 2017;44:1813-22; doi:10.3899/jrheum.170421)
\end{abstract}

Key Indexing Terms:

RHEUMATOID ARTHRITIS QUALITY OFCARE PHYSICIAN PRACTICE PATTERNS

From the Division of Rheumatology, Department of Medicine, and the Department of Community Health Sciences of the Cumming School of Medicine, and the McCaig Institute for Bone and Joint Health, University of Calgary, Calgary, Alberta; Arthritis Research Canada, Richmond; Division of Rheumatology, Department of Medicine, University of British Columbia, Vancouver, British Columbia; Division of Rheumatology, and the Department of Medicine and Laboratory Medicine and Pathobiology, and the Institute of Medical Science, and the Krembil Research Institute, University of Toronto, Toronto; Arthritis Alliance of Canada (AAC) Inflammatory Arthritis Models of Care, Toronto; William Osler Health System, Brampton; Canadian Institute of Health Research (CIHR) National Steering Committee, Ottawa; Outcome Measures in Rheumatology (OMERACT), Ottawa, Ontario; Hôpital

Maisonneuve-Rosemont, and the Institut de Recherche en Rhumatologie de Montréal, Université de Montréal, Montreal, Quebec, Canada; RAND

Corp., Santa Monica, California, USA.

C.E. Barber, MD, FRCPC, PhD, Assistant Professor, Division of

Rheumatology, departments of Medicine and Community Health Sciences, University of Calgary, Cumming School of Medicine, McCaig Institute for Bone and Joint Health, Research Scientist, Arthritis Research Canada; D.P. Mosher, MD, FRCPC, Professor, Chief, Division of Rheumatology, Department of Medicine, University of Calgary; V. Ahluwalia, MD, FRCPC, Consultant Rheumatologist, William Osler Health System; M. Zummer, MD, FRCPC, Chief, Rheumatology, Hôpital

Maisonneuve-Rosemont, Associate Professor, Université de Montréal;
D.A. Marshall, PhD, Professor, Department of Community Health Sciences, Cumming School of Medicine, Canada Research Chair (Health Services and Systems Research), Arthur J.E. Child Chair in Rheumatology Research, Department of Medicine, University of Calgary, McCaig Institute for Bone and Joint Health, and Arthritis Research Canada; D. Choquette, MD, FRCPC, Institut de Recherche en Rhumatologie de Montréal, Scientific Director, Rhumadata, Université de Montréal; D. Lacaille, MD, FRCPC, MHSc, Professor, Division of Rheumatology, Department of Medicine, University of British Columbia, Senior Scientist, Arthritis Research Canada; C. Bombardier, MD, FRCPC, Professor, Division of Rheumatology, University of Toronto; A. Lyddiatt, member, CIHR National Steering Committee, OMERACT patient research partner, AAC Inflammatory Arthritis Models of Care Executive Member; V. Chandran, MBBS, MD, DM, PhD, Assistant Professor, Department of Medicine and Laboratory Medicine and Pathobiology, Institute of Medical Science, Krembil Research Institute; D. Khodyakov, PhD, MA, BA, Senior Behavioral/Social Scientist, RAND Corp.; E. Dao, BS, RAND Corp.; C. Barnabe, MD, MSc, FRCPC, Associate Professor, departments of Medicine and Community Health Sciences, University of Calgary. Address correspondence to Dr. Claire E. Barber, University of Calgary, Rheumatology, HRIC Room 3AA20, 3280 Hospital Dr. NW, Calgary, AlbertaT2N 4N6, Canada.E-mail: cehbarbe@ucalgary.ca

Full Release Article. For details see Reprints and Permissions at jrheum.org Accepted for publication July 14, 2017.

Personal non-commercial use only. The Journal of Rheumatology Copyright @ 2017 . All rights reserved. 
In daily rheumatology practice, there is variability in the information documented from patient history and clinical examination, including the documentation of established quality measures in rheumatoid arthritis (RA) ${ }^{1,2}$. Variability in data collection creates challenges in maintaining complete patient records and monitoring care provision, and may also be a source of unwarranted variation in the provision of care. For example, guidelines suggest that rheumatologists should apply a treat-to- target approach to RA care ${ }^{3}$; however, this approach is inconsistently implemented outside the setting of clinical trials, largely because of inconsistencies in recording composite measures of disease activity ${ }^{4,5}$.

Further, electronic medical records (EMR) provide an opportunity for improving data collection practices. EMR are becoming increasingly common in $\mathrm{Canada}^{6}$, with $70 \%$ of rheumatologists using an EMR system. EMR may be used to improve point-of-care monitoring and decision making ${ }^{7,8}$, for quality monitoring $19,10,11$, and for research purposes ${ }^{12,13,14}$. The standardization of data elements collected during routine rheumatology visits could, therefore, be important not only for supporting best practices and high-quality RA care, but also for supporting rheumatology research efforts.

The Arthritis Alliance of Canada (AAC) is a nonprofit Canada-wide organization ${ }^{15}$ with the primary objective of improving the lives of Canadians living with arthritis. The AAC has worked since 2011 to develop and promote a pan-Canadian approach to models of care for patients with inflammatory arthritis, including RA ${ }^{16,17}$. During the course of this work, it was identified that variability in clinical data collection is a barrier to quality measurement. Therefore, as a starting point to encourage best practices and to facilitate future quality improvement efforts, a collaboration between individual investigators, the $\mathrm{AAC}$, and the Canadian Rheumatology Association (CRA) was formed to develop a Canadian RA Core Clinical Dataset (CAN-RACCD). Members of the RACCD Working Group are listed in Appendix 1.

\section{MATERIALS AND METHODS}

There were 3 phases to the development of the CAN-RACCD (Figure 1). During the first 2 phases, a total of 27 people participated, including 18 adult rheumatologists, 1 rheumatology fellow, 2 allied health professionals, 5 researchers/research staff, and a patient representative (number and type of participants in each phase outlined in Supplementary Data, available with the online version of this article). AAC members were invited by the organization to represent their provinces in this work and were selected based on their prior work in quality of care, development of rheumatology databases, and/or work in rheumatology EMR-based research.

Phase 1: Identification of a candidate set of core data elements. During Phase 1, an environmental scan of data collected for patients with RA in rheumatology practice was conducted. The objective of this scan was to (1) review existing data collection practices in clinical cohorts/registries in Canada, and in EMR; and (2) to summarize data elements that would need to be collected to assess practice against published quality measures. As part of the environmental scan, a 99-question survey was sent to principal investigators and/or research coordinators of 8 Canadian RA registries/cohorts to determine which data variables they routinely collect and how they are recorded. The questions were based on a survey of European registries conducted by Radner, et $a l^{18}$. The results were discussed at a meeting in October 2015. Nominal group technique, a structured brainstorming process ${ }^{19}$, was used to obtain feedback. In groups of 4 or 5 , participants discussed the results of the environmental scan, duplicate elements were harmonized, and a draft core clinical dataset was proposed.

Phase 2: Prioritization of data elements for inclusion. During a second meeting in February 2016, the draft elements from Phase 1 were presented to 20 AAC members (names listed in Supplementary Data, available with the online version of this article) who prioritized the elements for inclusion. High-priority elements (critical to include, with only 1 way to collect the data) were assigned to the final candidate set, and low-priority elements (not essential for care provision) were eliminated from consideration. Elements of indeterminate priority (unclear whether should be included and/or more than 1 way to collect the data element) were subject to a literature review. Targeted literature reviews were completed according to a predefined protocol to gather information on whether collection of the data element was recommended by guidelines and/or quality indicators and the recommended recording methods. A summary report was prepared (available upon request) and discussed by 20 participants during 2 teleconferences to determine whether the elements should be considered for inclusion in the CAN-RACCD.

Phase 3: Modified Delphi consensus process to select the final core clinical dataset. During Phase 3, an online modified Delphi exercise was conducted to select the final set with broad input. The 3-round modified Delphi was conducted using an electronic platform called ExpertLens (RAND Corp. $)^{20,21,22}$. During Round 1, participants rated the importance and feasibility of individual elements on a Likert scale of 1 to 9: "How important is it to include this element in the core data set for the provision of care and clinical decision making for rheumatoid arthritis?" and "How feasible is it to collect this element routinely on patients with rheumatoid arthritis?" where 1 is not important/feasible and 9 is very important/very feasible. Subgroup randomization based on data element themes was used to ensure an even response distribution for all groups of questions during the process. During Round 2, participants reviewed their ratings of the elements in comparison to the group ratings, and participated in an anonymous, asynchronous, online moderated discussion to resolve any disagreements and build consensus. In Round 3, after considering the results of the first 2 rounds, participants were asked to provide a final rating to the elements using Round 1 questions.

Elements were included in the final set if they were deemed important and feasible to collect (median ratings for both of $\geq 6.5$ ) without disagreement according to the RAND/University of California at Los Angeles Appropriateness Method handbook ${ }^{23}$

Fifty potential participants for the modified Delphi consensus process were invited to participate using different strategies from the following groups: rheumatologists, people living with arthritis, and allied health providers including Advanced Practitioners in Arthritis Care (ACPAC) Extended Role Practitioners, a special designation of highly trained rheumatology allied health professionals in Canada ${ }^{24,25}$. Patient participants were recruited through 2 arthritis advocacy organizations: the Arthritis Patient Advisory Board and the Canadian Arthritis Patient Alliance. To ensure a diversity of opinion, the AAC, the CRA, and the ACPAC program director were asked to nominate potential participants.

Ethics. The project was approved by the University of Calgary Ethics (ID: REB16-1551) and deemed exempt from review by the RAND's Human Subjects Protection Committee (ID: 2016-0663).

\section{RESULTS}

Phase 1: Identification of a candidate set of core data elements. Representatives from 7 of the 8 Canadian cohorts/registries participated in the survey. Summary results are presented in Table 1 (detailed results of the survey are shown in the Supplementary Data, available with the online

Personal non-commercial use only. The Journal of Rheumatology Copyright @ $\odot 2017$. All rights reserved 
Phase 1: Identification of a candidate set of RA core data elements.

Description: Environmental scan of data collected in rheumatology was used to draft a candidate list of core data elements.

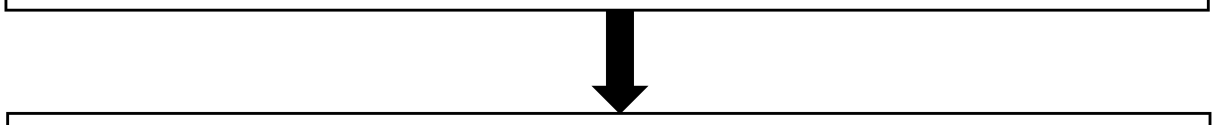

Phase 2: Prioritization of data elements for inclusion.

Description: Candidate data elements categorized as high, low, or indeterminate priority. Elements of indeterminate priority were assigned for literature review to determine concordance with guidelines/quality measures.

Participants reviewed and discussed the results of the literature review over

2 conference calls and further elements were eliminated or refined.

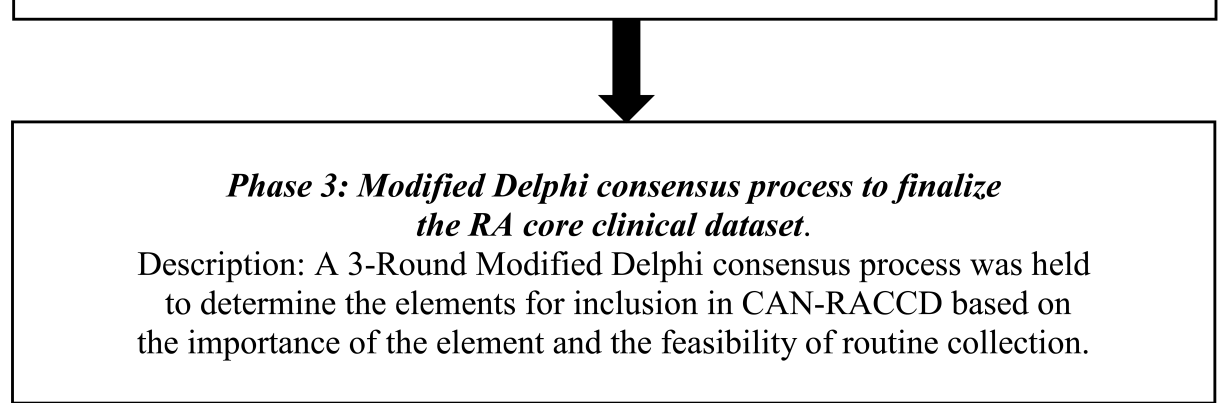

Figure 1. Methods for development of the Canadian Rheumatoid Arthritis Core Clinical Dataset (CAN-RACCD). RA: rheumatoid arthritis.

version of this article). Variation between cohorts/registries in data collection methods was evident for most data items [e.g., smoking status, tender and swollen joints counts (TJC and SJC), evaluation of physical function, and quality of life].

Data elements required for the provision of high-quality care in RA were identified in a previously published systematic review ${ }^{26}$. As a result of the meeting in Phase 1, during which the data elements from the systematic review and survey were discussed, a list of 41 data elements in 10 categories was proposed, including demographics, dates (e.g., dates of referral, first visit, diagnosis, symptom onset), clinical data (e.g., height, weight, disease activity), comorbidities, smoking status, patient-reported outcomes, medications, laboratory and radiographic data, and vaccinations (Table 2).

Phase 2: Prioritization and refinement of data elements for inclusion. During the prioritization exercise in Phase 2, 10 data elements were deemed high priority for inclusion in the set: date of birth, sex, 28 tender and swollen joint counts, provider global assessment, baseline serology, C-reactive protein (CRP), tuberculosis (TB) screening, and hepatitis $\mathrm{B}$ and $\mathrm{C}$ serology (Table 2). Three items were deemed low priority and were excluded: adverse events, quality of life, and mental health status. While both quality of life and mental health status were considered important outcomes, the routine and standardized collection of these elements was not considered feasible as part of daily care in RA. Similarly, standardized collection of adverse events using an excepted framework was also regarded as beyond the scope of the core set. The remainder of the variables were assigned for literature review.

A number of refinements was made to the list of data elements based on the targeted literature reviews and are summarized here.

- Demographics: Ethnicity and postal code were excluded as the process of documenting these elements could not be linked to improved quality of care based on our literature review of guidelines and quality measures. Additionally, while identifying working status was considered important, recording this element routinely in a standardized fashion was perceived to be of low feasibility and more appropriate in research-specific endeavors.

- Dates: The date of symptom onset had initially been excluded in Phase 1 owing to concerns about the accuracy of collection; however, it was reintroduced with the rationale that the duration of symptoms was critical to the diagnosis of RA and is part of the 2010 classification criteria for $\mathrm{RA}^{27}$.

- Clinical data: Weight and height (for body mass index

Personal non-commercial use only. The Journal of Rheumatology Copyright (c) 2017. All rights reserved. 
Table 1. Summary of survey results listing of types of data collected in 7 Canadian Rheumatoid Arthritis Registries/Cohorts*.

$\begin{array}{ccc}\text { Types of Data } & \text { Frequency and Variation of Data Collection in the Existing Cohorts } \\ \text { Routinely Collected and Routinely Collected but Infrequently } \\ \text { Limited Variation in } \\ \text { Collection Methods }\end{array}$

\begin{tabular}{ll}
\hline Demographic & \\
Sex & $X$ \\
Age & $X$ \\
Postal code & $X$ \\
Ethnicity & $X$
\end{tabular}

Socioeconomic variables (income, level of education, years of education, employment, prescription coverage)

Reporting disease duration (patient vs physician)

Comorbidities

Comorbidity type, crude number, date of diagnosis, therapy of comorbidity

Mental health

$\mathrm{X}$

$\mathrm{X}$

$\mathrm{X}$

Environmental exposures

Smoking (yes/no, cigarettes per day, current/previous never, pack/yr history)

Investigations

Serology (RF and anti-CCP)

Acute-phase reactants (ESR, CRP)

Radiographs of hands and feet

Disease activity

Swollen joint counts (SJC 28, 66, 44)

Tender joint counts (TJC 28, 32, 44)

Composite disease activity score (DAS28-ESR, DAS-28 CRP, SDAI, CDAI)

Evaluator global assessment of disease activity (related to arthritis, within the last week, total today, global health)

Patient's global assessment of disease activity (related to arthritis, within the last week, total today, global health)

Patient-reported disease activity (RADAI or other)

Patient-reported outcomes

Health-related Quality of Life (SF-36, EQ-5D, or other)

Patient assessment of function (HAQ, HAQ-DI, CLINHAQ, PCS of SF-36)

Pain (within last week, related to arthritis, general pain)

Fatigue (VAS, numerical scale)

Medications

RA-specific treatment (categories of treatment and type, dose, frequency, duration

of use, stop reason; DMARD, biologics, steroids, NSAID)

Non-RA medications

Adverse events (serious, any, only if drug-related)

Other

Joint surgery

BMI

Vaccinations

Pregnancy

Genetic markers
$\mathrm{X}$

$\mathrm{X}$

$\mathrm{X}$
$\mathrm{X}$

$\mathrm{X}$

X

X

X

X

X

X

X

$\mathrm{X}$

$\mathrm{X}$

X

X

X

X

X

$\mathrm{X}$

* The 7 Canadian Rheumatoid Arthritis Cohorts include Rheum4U (Calgary); Rhumadata (Montreal and Quebec City); Rapport (Calgary); Early Inflammatory Arthritis Cohort (Calgary); Ontario Best Practices Research Initiative (OBRI, Ontario); Canadian Early Arthritis Cohort (CATCH). Anti-CCP: anticyclic citrullinated peptide antibodies; BMI: body mass index; CDAI: Clinical Disease Activity Index; CLINHAQ: Clinical Health Assessment Questionnaire; CRP: C-reactive protein; DAS28: 28-joint Disease Activity Score; RA: rheumatoid arthritis; DMARD: disease-modifying antirheumatic drugs; ESR: erythrocyte sedimentation rate; HAQ: Health Assessment Questionnaire; HAQ-DI: Health Assessment Questionnaire-Disability Index; NSAID: nonsteroidal antiinflammatory drugs; PCS: physical component summary (from SF-36 survey); RADAI: Rheumatoid Arthritis Disease Activity Index; RF: rheumatoid factor; SDAI: Simplified Disease Activity Index; SF-36: Medical Outcomes Study Short Form-36; SJC: swollen joint count; TJC: tender joint count; VAS: visual analog scale.

calculation) were discussed. Recording of weight was recommended at baseline and periodically as part of routine care, consistent with guidelines and quality measures ${ }^{28,29}$. Height was recommended at baseline and yearly measurement in a subset of patients at risk for osteoporosis. Periodic blood pressure measurement (at a minimum yearly) was recommended [more frequently in patients taking specific agents, e.g., nonsteroidal antiinflammatory drugs (NSAID) and leflunomide $]^{28,29}$.

- Disease activity: Regular measurement of RA disease

Personal non-commercial use only. The Journal of Rheumatology Copyright @ 2017. All rights reserved. 
Table 2. Candidate data elements for inclusion into core set and decisions made during each development phase.

\begin{tabular}{|c|c|c|c|}
\hline Data Element Theme Proposed during Phase 1 & $\begin{array}{l}\text { Phase 2: Prioritization } \\
\text { Exercise* }\end{array}$ & $\begin{array}{l}\text { Decision following Targeted } \\
\text { Literature Reviews and Discussion }\end{array}$ & $\begin{array}{l}\text { Phase 3: Final Inclusion } \\
\text { following Online } \\
\text { Modified Delphi }\end{array}$ \\
\hline \multicolumn{4}{|l|}{ Demographics } \\
\hline Sex & High priority & Retained & Include \\
\hline Ethnicity & Indeterminate & Excluded & - \\
\hline Postal code & Indeterminate & Excluded & - \\
\hline Date of referral to rheumatology & Indeterminate & Retained & Include \\
\hline Date of diagnosis & Indeterminate & Retained & Include \\
\hline Date of first visit & Indeterminate & Retained & Include \\
\hline Date of symptom onset & Initially low priority & Re-discussed and re-included & Include \\
\hline \multicolumn{4}{|l|}{ Clinical data } \\
\hline Height & Indeterminate & Retained & Include \\
\hline Weight & Indeterminate & Retained & Include \\
\hline Provider global & High priority & Retained & Include \\
\hline Composite disease activity measures (e.g., DAS28, SDAI, CDAI) & I) Indeterminate & Retained & Include \\
\hline \multicolumn{4}{|c|}{ Comorbidities } \\
\hline $\begin{array}{l}\text { Comorbidity types: CVD, HTN, dyslipidemia, DM, infections } \\
\text { and TB exposure, lung disease, malignancies, CKD }\end{array}$ & Indeterminate & Retained and list refined & Include \\
\hline \multicolumn{4}{|l|}{ Smoking status } \\
\hline Smoking (requires standardization) & Indeterminate & Retained and concept expanded & Include \\
\hline \multicolumn{4}{|l|}{ Patient-reported outcomes } \\
\hline Patient global & Indeterminate & Retained & Include \\
\hline Pain & Indeterminate & Retained & Include \\
\hline Fatigue & Indeterminate & Retained & Include \\
\hline Morning stiffness & Indeterminate & Excluded & - \\
\hline Mental health status (e.g., depression screen) & Low priority & - & - \\
\hline Serology (RF and anti-CCP) & High priority & Retained & Include \\
\hline ESR & Indeterminate & Retained & Include \\
\hline CRP & High priority & Retained & Include \\
\hline ALT & Indeterminate & Retained & Include \\
\hline $\mathrm{CBC}$ & Indeterminate & Retained & Include \\
\hline- & $\mathrm{sCr}$ added & Retained & Include \\
\hline TB screening (skin test) & High priority & Retained & Include \\
\hline Hepatitis B serology & High priority & Retained & Include \\
\hline Hepatitis C serology & High priority & Retained & Include \\
\hline \multirow[t]{2}{*}{ Chest radiograph } & Indeterminate & Retained & Include \\
\hline & diographs hand/feet added & Retained & Include \\
\hline \multicolumn{4}{|l|}{ Vaccinations } \\
\hline Influenza & Indeterminate & Borderline** & Exclude \\
\hline Pneumococcal & Indeterminate & Borderline** & Exclude \\
\hline Others not yet specified & Zoster vaccine added & Borderline ${ }^{* *}$ & Exclude \\
\hline
\end{tabular}

${ }^{*}$ During the Phase 2 prioritization exercise, participants were asked to rate each element as high priority (include and only one way to capture the element), low priority (exclude, may be important for research but not routine care), or indeterminate (unclear if important or more than one way to collect the element).

** Based on the review conducted and participation it was unclear whether vaccines should be retained and it was determined this should be reviewed during the modified Delphi exercise. ALT: alanine aminotransferase; anti-CCP: anticyclic citrullinated peptide antibodies; CBC: complete blood count; CRP: C-reactive protein; DMARD: disease-modifying antirheumatic drug; ESR: erythrocyte sedimentation rate; RF: rheumatoid factor; sCr: serum creatinine; SJC: swollen joint count; TJC: tender joint count; TB: tuberculosis; DAS28: 28-joint Disease Activity Score; SDAI: Simplified Disease Activity Index; SF-36: Medical Outcomes Study Short Form-36; VAS: visual analog scale; CVD: cardiovascular disease; HTN: hypertension; DM: diabetes mellitus; CKD: chronic kidney disease; NSAID: nonsteroidal antiinflammatory drugs.

Personal non-commercial use only. The Journal of Rheumatology Copyright $\subset$ 2017. All rights reserved. 
activity using a composite validated disease activity measure is recommended in RA guidelines $3,30,31,32$ and is also an RA quality measure ${ }^{1}$. There is currently, however, no single composite measure of disease activity that is preferred or recommended over another ${ }^{33}$. In reviewing disease activity measurement, our participants did not make a recommendation about which specific measure should be routinely included in a core set, but suggested the following: (1) a validated disease activity measure should be included and calculated routinely on patients with RA [e.g., either 28-joint Disease Activity Score (DAS28), Clinical Disease Activity Index (CDAI), or Simplified DAI (SDAI)]; (2) at a minimum, the elements of a CDAI should be collected because this requires no additional laboratory values (includes TJC 28 and SJC 28, patient global disease activity, and provider global disease activity); (3) validated questions should be used to inquire about patient global disease activity or patient's global assessment depending on whether the CDAI/SDAI, DAS28, or other measure is used; (4) periodic collection of ESR and/or CRP. One inflammation marker was not recommended over the other given that ESR is not available in all centers and some centers prefer collection of both.

- Comorbidities: The list of comorbidities was refined during this phase based on a consensus statement ${ }^{34}$ and evidence-based recommendations ${ }^{35}$ for the management of comorbidities in RA. The 10 categories, including important subcategories, were suggested for inclusion (Table 3). For clinical reasons, an "other" category was included to record other relevant but rare comorbidities in each of the 10 categories.

- Smoking status: Smoking status was considered an important element to note and is part of a quality measure set for RA cardiovascular care ${ }^{29}$. It was suggested to gather "never, ever and current" smoking status. There was debate about including the date of smoking cessation, the smoking start date, and the current smoking amount, and these concepts were further evaluated in Phase 3.

- Patient-reported outcomes: Recording pain was recommended and is included in the original American College of Rheumatology (ACR) RA core disease activity set ${ }^{36}$. It was suggested that a numerical rating scale (NRS) of 0 to 10 should be used with the following standard question ${ }^{37}$ : "Please mark/circle the number, from 0 to 10 , which indicates how much pain you have had in the past week because of your arthritis, with 0 being 'no pain' and 10 being 'pain as bad as it could be."”

Fatigue was also considered important to record and a number of validated scores were considered ${ }^{38}$. The Bristol Rheumatoid Arthritis Fatigue NRS for severity, effect, and coping were considered the simplest (it is also available in both English and French) $)^{39,40,41,42}$.

Morning stiffness was considered, but ultimately excluded despite its perceived importance, because of high variability in how this question is asked, measured, and understood. It
Table 3. Comorbidities considered for inclusion in the core dataset for RA.

\begin{tabular}{|c|c|}
\hline Major & Subcategories \\
\hline Cardiovascular & $\begin{array}{l}\text { Myocardial infarction } \\
\text { Coronary artery disease } \\
\text { Congestive heart failure } \\
\text { Hypertension } \\
\text { Cerebrovascular disease } \\
\text { Other }\end{array}$ \\
\hline Chronic kidney disease & $\begin{array}{l}\text { Renal insufficiency } \\
\text { Dialysis } \\
\text { Other }\end{array}$ \\
\hline Chronic liver disease & $\begin{array}{l}\text { Cirrhosis } \\
\text { Fatty Liver } \\
\text { Other }\end{array}$ \\
\hline Cancer & $\begin{array}{l}\text { Solid tumors: e.g., lung, prostate, pancreas, } \\
\text { breast, colon, melanoma, other } \\
\text { Hematologic: non-Hodgkin's lymphoma, } \\
\text { leukemia, Hodgkin's lymphoma, other }\end{array}$ \\
\hline Respiratory & $\begin{array}{l}\text { Chronic obstructive pulmonary disease } \\
\text { Asthma } \\
\text { Interstitial lung disease } \\
\text { Other }\end{array}$ \\
\hline Infections & $\begin{array}{l}\text { Tuberculosis } \\
\text { Hepatitis B } \\
\text { Hepatitis C } \\
\text { HIV } \\
\text { Other serious infection }\end{array}$ \\
\hline Metabolic & $\begin{array}{l}\text { Diabetes } \\
\text { Thyroid disease }\end{array}$ \\
\hline Osteoporosis & - \\
\hline Mental illness & $\begin{array}{l}\text { Depression } \\
\text { Anxiety } \\
\text { Other }\end{array}$ \\
\hline Gastrointestinal & $\begin{array}{l}\text { Peptic ulcer disease } \\
\text { Other }\end{array}$ \\
\hline
\end{tabular}

RA: rheumatoid arthritis; HIV: human immunodeficiency virus.

is also subject to cultural and language interpretations. Finally, stiffness overlaps greatly with pain and fatigue, and has not been included in American or Canadian guidelines or quality metrics.

Measuring physical function in RA was regarded as important in prognostication ${ }^{3}$ and is recommended in routine monitoring of response to treatment, and is an ACR quality measure ${ }^{1}$. While there are many patient-reported tools used to assess physical function, the Health Assessment Questionnaire (HAQ) II was recommended because it has better psychometric properties than other versions of the $\mathrm{HAQ}$, and is shorter and easier to use in clinical practice ${ }^{43}$. - Medications: There was agreement that to provide care, physicians need to collect, at each visit, the name, dosage, and mode of administration of disease-modifying antirheumatic drugs, biologics, small molecule inhibitors, NSAID, and corticosteroids. While intraarticular and intramuscular glucocorticoids are frequently administered, documentation of their administration poses feasibility challenges and was not considered essential for care quality.

Personal non-commercial use only. The Journal of Rheumatology Copyright $@$ 2017. All rights reserved. 
- Laboratory and radiographic data: For disease and treatment monitoring, baseline and periodic measurement (e.g., q3-6 mos) of the following laboratory tests was suggested: alanine aminotransferase (ALT), complete blood count (CBC), and serum creatinine. Although the CRA recommends frequent hand and foot radiographs (every 6-12 mos) in early RA and at longer intervals in patients with established disease ${ }^{3}$, this was felt to be beyond the scope of the core set. However, documentation baseline radiographs of affected joints (e.g., hands/wrists and ankles/feet) and whether erosions were present was felt to be important. Additionally, a baseline chest radiograph was deemed important to document in specific clinical scenarios (e.g., premethotrexate ${ }^{3}$, positive TB screening, prebiologics, or at baseline in those with other risk factors for lung disease including smokers).

Baseline documentation of serology including rheumatoid factor and anticyclic citrullinated peptide antibodies was considered important to include because it assists with diagnosis and prognosis of $\mathrm{RA}^{3}$. It was recognized that some centers may not have ready access to these tests. Finally, TB screening prebiologic is consistent with CRA guidelines ${ }^{3}$ and inclusion reinforces good practice.

- Vaccination: Consensus could not be reached in Phase 2. Consideration of inclusion of the influenza, pneumococcal, and shingles vaccines was retained for further debate/review during the final modified Delphi (Phase 3).

Phase 3: Modified Delphi to finalize the core set. Forty-seven of the 50 invited participants (94\%) joined at least 1 round of the modified Delphi: 38 in Round 1 (76\%), 30 in Round 2 $(60 \%)$ and 41 in Round 3 (82\%). Demographic characteristics of the participants were recorded in Round 1 (Table 4). Based on ratings from Round 1 and the discussion in Round 2, a few minor changes to the set were proposed and re-rated in Round 3. First, inclusion of a complete (rather than a partial) joint count (a TJC 68 and SJC 66) was proposed, because disease activity of the feet would otherwise be missed. Second, because not all participants were familiar with the HAQ II, it was suggested that any validated measure of physical function could be included. Last, while recording whether a chest radiograph was completed, participants wanted an option to indicate whether it was abnormal.

Round 3 results of the Delphi are presented in the Supplementary Data (available with the online version of this article). All proposed elements were rated of high importance ( $\geq 6.5$ on scale of 1-9) and high feasibility with the following exceptions: routinely recording additional details about smoking habits beyond never/ever/current was felt to have low importance or feasibility; while recording level of fatigue met the threshold for inclusion, measuring effect and coping of fatigue did not; similarly, noting vaccine status did not meet threshold for inclusion in the set; and finally, recording all comorbidities listed was rated as important and feasible with the exception of lower feasibility ratings for documentation of mental health conditions.
Table 4. Demographic characteristics of Round 1 participants. Data are n (\%).

$\begin{array}{lc}\text { Participant type, } \mathrm{n}=37^{*} & \\ \text { Rheumatologist } & 26(70) \\ \text { Person living with arthritis } & 4(11) \\ \text { Allied health professional } & 2(5) \\ \text { ACPAC ERP** } & 5(14) \\ \text { Province }{ }^{* * *} & \\ \text { British Columbia } & 5(14) \\ \text { Alberta } & 5(14) \\ \text { Manitoba } & 1(3) \\ \text { Ontario } & 16(43) \\ \text { Quebec } & 6(16) \\ \text { New Brunswick } & 1(3) \\ \text { Nova Scotia } & 2(5) \\ \text { Newfoundland and Labrador } & 1(3) \\ \text { Physician characteristics, } \mathrm{n}=26 & \\ \text { Years in practice } & \\ <5 \text { yrs } & 2(8) \\ 5-10 \text { yrs } & 6(23) \\ \text { 11-20 yrs } & 10(38) \\ \text { > 21 yrs } & 8(31) \\ \text { Practice setting } & \\ \text { Community } & 7(27) \\ \text { University-based: clinical/teaching } & 15(58) \\ \text { University-based: research } & 2(8) \\ \text { Other } & 2(8) \\ \text { Participation in other phases of the project, } \mathrm{n}=36 & 10(28)\end{array}$

*While 38 individuals participated in Round 1, only 37 completed demographic information. ${ }^{* *}$ Some of the ACPAC ERP indicated that they were nurses and ACPAC ERP. They have been categorized as ACPAC ERP for this table. ${ }^{* * *}$ There were no respondents from Saskatchewan, Prince Edward Island, Nunavut, Yukon Territory, or Northwest Territories. ACPAC ERP: Advanced Clinician Practitioner in Arthritis Care Extended Role Practitioner.

\section{DISCUSSION}

The CAN-RACCD represents a consensus on core data elements that should be routinely collected in clinical practice for the care of patients with RA. The set includes 9 categories: demographic, dates, clinical data, disease activity, comorbidities, smoking status, patient-reported outcomes, medications, and laboratory and radiographic data; with 49 individual data elements for collection.

This work represents the first step in facilitating efforts for standardized measurement for the purpose of improving quality of care of patients with RA in routine clinical practice. This work may also benefit efforts in many provinces to use EMR for research purposes, because harmonized and consistent data collection is necessary for research. For provinces and providers without an EMR or who have EMR that are not specialty-specific, this work may be useful when advocating for specialty EMR platforms and rheumatology tools including disease activity calculators.

Establishing a core dataset for RA is not a new concept, although it has generally been done for research purposes. For example, a recent review and survey of 27 European RA cohorts/registers from 16 countries was conducted to determine the consistency and use of data items ${ }^{18}$. The study

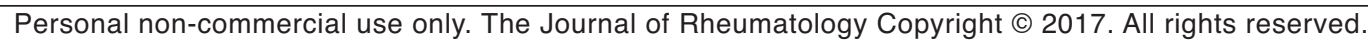


asked respondents to rate their usage of each data item for research purposes, how often they used it, and to also rank the 5 most essential items collected across the 25 studies. This list had significant overlap with the CAN-RACCD, indicating potential use of the CAN-RACCD for research. Areas of high overlap between the sets included measurement of disease activity, treatment, function, serology, and inflammatory markers and comorbidities. One area identified in the European cohorts and registries, but not included in CAN-RACCD, was adverse events; this may reflect the pharmacovigilance mandate of many European cohorts, in contrast to CAN-RACCD. Fatigue was included in the RACCD, but not frequently collected or rated as important in the European survey ${ }^{18}$, although it was deemed important for patients and is part of the Outcome Measures in Rheumatoid Arthritis Clinical Trials (OMERACT) RA Core Domain $\mathrm{Set}^{44}$. The review concluded that data definitions were heterogeneous even when the same element was collected, with the most heterogeneous items being smoking status, patient's global assessment of disease activity, and ethnicity. Radner, et al also noted that while assessment of disease activity using a composite score was universally recorded by the cohorts/registers, there was variability in the choice of instrument ${ }^{18}$.

In 2007, Pincus and Sokka proposed a 3-page Standard Protocol to Evaluate RA (SPERA) ${ }^{45}$. While SPERA was designed for use in clinical care and research, it is unclear how frequently it has been used. Further, while the contents followed core domains for longterm outcome studies based on an OMERACT conference ${ }^{46}$, it is unclear how domains collected were selected for inclusion in the set. While there is some overlap with the CAN-RACCD because both collect information on disease characteristics and medications, SPERA does not include patient- reported outcomes and is not consistent with a treat-to-target approach because composite measures of disease activity are not included either.

More recently, the European League Against Rheumatism has embarked upon a similar exercise to develop recommendations for the standardized content and structure of core data to facilitate patient care and research in $\mathrm{RA}^{47}$. However, to our knowledge this work has not been published to date.

During the development of the CAN-RACCD, broad national input was obtained with excellent participation rates across all phases of development. However, a few limitations to this work should be noted. First, there was some overlap between participants from earlier stages of the project and the final phase. This was by design because some participants expressed interest but could only attend 1 meeting; however, they were able to participate in the final online modified Delphi. It is possible this resulted in potential bias of results from more engaged participants who may have been willing to rate data elements as more important and/or feasible to collect than the average rheumatologist. It was also more challenging to recruit rheumatologists in community practice. It should also be noted that consensus in phases 1-3 could not be reached on some elements, for example, recommending a preferred composite measure of disease activity or preferred instrument for measuring function. This likely reflects practice variation, which is not unique to Canada because the ACR recommends more than 1 tool for disease activity and functional status measurement in current quality measurement efforts 1,48 .

The list of core elements in the CAN-RACCD are rated as important and feasible to collect by rheumatology care providers and people living with arthritis from across Canada. Future work will focus on development of appropriate variables within EMR and on development of quality metrics based on some of the elements that are most closely linked to better patient outcomes.

\section{ACKNOWLEDGMENT}

Project support for this work was provided by the following individuals: Jaimie Coish, Executive Director, Arthritis Alliance of Canada, Toronto, Ontario; Lina Gazizova, Project Manager, Arthritis Alliance of Canada; Sandy Kennedy, Project Support, Arthritis Alliance of Canada; Dan Devoe, Project Support, University of Calgary, Calgary, Alberta, Canada.

\section{ONLINE SUPPLEMENT}

Supplementary material accompanies the online version of this article.

APPENDIX 1. List of collaborators: RACCD ExpertLens Working Group (in alphabetical order): Pooneh Akhavan, MD, MSc, FRCPC, Division of Rheumatology, Department of Medicine of University of Toronto, Mount Sinai Hospital, Toronto, Ontario; Arundip Asaduzzaman, MD, FRCPC, Rheumatologist, Toronto, Ontario; J. Antonio Aviña-Zubieta, MD, MSc, $\mathrm{PhD}$, Associate Professor, Division of Rheumatology, Department of Medicine, University of British Columbia, Vancouver, British Columbia, and Research Scientist, Arthritis Research Centre of Canada; Cory Baillie, MD, FRCPC, Assistant Professor, University of Manitoba, Winnipeg, Manitoba, and Past President, Canadian Rheumatology Association; Gilles Boire, MD, MSc, Professor, Department of Medicine, Rheumatology Division, Faculty of Medicine and Health Sciences, Centre Intégré Universitaire de Santé et de Services Sociaux de l'Estrie-Centre Hospitalier Universitaire de Sherbooke, Sherbrooke, Quebec; Denise Boone, RN, $\mathrm{MScN}$, ACPAC, Nurse Specialist Rheumatology, The Ottawa Hospital, Ottawa, Ontario; Julie Brophy, MD, FRCPC, Rheumatologist, Guelph, Ontario; Jennifer Burt, PT, Rheumatology Services, St. Clare's Mercy Hospital, Eastern Health, St. John's, Newfoundland and Laborador; Vinod Chandran, MBBS, MD, DM, PhD, Assistant Professor, Department of Medicine and Laboratory Medicine and Pathobiology, University of Toronto, and Institute of Medical Science, University of Toronto, and Krembil Research Institute, Toronto, Ontario; Alf Cividino, MD, FRCPC, Professor, Division Director, Rheumatology, McMaster University, Hamilton, Ontario; Kelly English, Co-Chair, Arthritis Patient Advisory Board to Arthritis Research Canada; Derek Halaand, MD, FRCPC, MSC, Assistant Clinical Professor, Division of Clinical Immunology/Allergy and Rheumatology, McMaster University, Hamilton, Ontario; Boulos Haraoui, MD, FRCPC, Associate Professor, Division of Rheumatology, Department of Medicine, University of Montreal, Carol A. Hitchon, MD, FRCPC, MSC, Associate Professor, Max Rady College of Medicine, Rady Faculty of Health Sciences, University of Manitoba, Winnipeg, Manitoba; Joanne Homik, MD, MSc, FRCPC, Associate Professor, Department of Medicine, University of Alberta, Edmonton, Alberta; Steven Katz, MD, FRCPC, Associate Clinical

Personal non-commercial use only. The Journal of Rheumatology Copyright (C) 2017. All rights reserved. 
Professor, Department of Medicine, University of Alberta, Edmonton, Alberta; Raheem Kherani, MD, FRCPC, MHPE, BSc (Pharm), Clinical Assistant Professor, Department of Medicine, University of British Columbia, Vancouver, and Rheumatologist, West Coast Rheumatology Associates, Richmond, and Medical Lead, Arthritis Program, GF Strong Rehabilitation Centre, Vancouver, British Columbia; Barry Koehler, MD, FRCPC, Clinical Professor Emeritus, Division of Rheumatology, Department of Medicine, University of British Columbia, Vancouver, British Columbia; Tabitha Kung, MD, FRCPC, MPH, Assistant Professor, Division of Rheumatology, Department of Medicine, Queen's University, Kingston, Ontario; Juris Lazovskis, MD, Assistant Professor, Department of Medicine, Dalhousie University, Halifax, and Rheumatologist, Sydney, Cape Breton, Nova Scotia; Patrick Liang, MD, FRCPC, Associate Professor, Department of Medicine, Rheumatology Division, University of Sherbrooke, Sherbrooke, Quebec; Theresa Lupton, RN, CCRP, Nurse Clinician Rheumatology, Alberta Health Services; Anne MacLeod, BscPT, MPH, ACPAC, Arthritis Society and a shared-care Community Rheumatology Practice, Assistant Professor, Northern Ontario School of Medicine, Thunder Bay, Ontario; Rashmi Mandhane, BScPT, ACPAC, University of Alberta Hospital, Alberta Health Services, Edmonton, Alberta; Annette McKinnon, Patient, Member of Canadian Arthritis Patient Alliance (CAPA), Member of Arthritis Patient Advisory Board (APAB); Sylvie Ouellette, MD, FRCPC, Assistant Professor, Dalhousie University, Halifax, Nova Scotia, and Clinical Assistant Professor, Memorial University of Newfoundland, St. John's, Newfoundland and Laborador, and Rheumatologist, The Moncton Hospital, Moncton, New Brunswick; Janet Pope, MD, MPH, FRCPC, Professor of Medicine, Division of Rheumatology, University of Western Ontario, London, Ontario; Dawn Richards, PhD, Rheumatoid arthritis patient, Vice President, Canadian Arthritis Patient Alliance; Sophie Roux, MD, PhD, Director, Rheumatology Division, Department of Medicine, University of Sherbrooke, Sherbrooke, Quebec; Evelyn Sutton, MD, FRCPC, Professor, Department of Medicine, Division of Rheumatology, Dalhousie University, Halifax, Nova Scotia; Trudy Taylor, MD, FRCPC, Assistant Professor, Department of Medicine, Division of Rheumatology, Dalhousie University, Halifax, Nova Scotia; Regina Taylor-Gjevre, MD, FRCPC, MSc, Professor, Division of Rheumatology, Department of Medicine, University of Saskatchewan, Saskatoon, Saskatchewan; Jean-Luc Tremblay, MD, FRCPC, Rheumatologist, Chargé d'enseignement clinique, CIUSSS MCQ Centre Hospitalier Affilié Universitaire Régional, Trois-Rivières, Quebec; Hazel Wilson, Patient Partners in Arthritis, London, Ontario, Canada.

\section{REFERENCES}

1. Yazdany J, Myslinski R, Miller A, Francisco M, Desai S, Schmajuk $\mathrm{G}$, et al. Methods for developing the American College of Rheumatology's electronic clinical quality measures. Arthritis Care Res 2016;68:1402-9.

2. Barber CE, Esdaile JM, Martin LO, Faris P, Barnabe C, Guo S, et al. Gaps in addressing cardiovascular risk in rheumatoid arthritis: assessing performance using cardiovascular quality indicators. J Rheumatol 2016;43:1965-73.

3. Bykerk VP, Akhavan P, Hazlewood GS, Schieir O, Dooley A, Haraoui B, et al. Canadian Rheumatology Association recommendations for pharmacological management of rheumatoid arthritis with traditional and biologic disease-modifying antirheumatic drugs. J Rheumatol 2012;39:1559-82.

4. Taylor A, Bagga H. Measures of rheumatoid arthritis disease activity in Australian clinical practice. ISRN Rheumatol 2011;2011:437281.

5. Haraoui B, Bensen W, Bessette L, Le Clercq S, Thorne C, Wade J. Treating rheumatoid arthritis to target: a Canadian physician survey. J Rheumatol 2012;39:949-53.

6. Barber C, Jewett L, Ahluwalia V, Averns H, Baillie C, Badley E, et al. Measuring the rheumatologist workforce in Canada: stand up and be counted! J Rheumatol 2016;43:1204-5.
7. Dean NC, Jones BE, Jones JP, Ferraro JP, Post HB, Aronsky D, et al. Impact of an electronic clinical decision support tool for emergency department patients with pneumonia. Ann Emerg Med 2015; 66:511-20.

8. Katzan IL, Fan Y, Speck M, Morton J, Fromwiller L, Urchek J, et al. Electronic Stroke CarePath: integrated approach to stroke care. Circ Cardiovasc Qual Outcomes 2015;6 Suppl 3:S179-89.

9. Baker DW, Brown T, Lee JY, Ozanich A, Liss DT, Sandler DS, et al. A multifaceted intervention to improve influenza, pneumococcal, and herpes zoster vaccination among patients with rheumatoid arthritis. J Rheumatol 2016;43:1030-7.

10. Yazdany J, Bansback N, Clowse M, Collier D, Law K, Liao KP, et al. The Rheumatology Informatics System for Effectiveness (RISE): a national informatics-enabled registry for quality improvement. Arthritis Care Res 2016;68:1866-73.

11. Shaw SJ, Jacobs B, Stockwell DC, Futterman C, Spaeder MC. Effect of a real-time pediatric ICU safety bundle dashboard on quality improvement measures. Jt Comm J Qual Patient Saf 2015;41:414-20.

12. Janssens HJ, Arts PG, Schalk BW, Biermans MC. Gout and rheumatoid arthritis, both to keep in mind in cardiovascular risk management: A primary care retrospective cohort study. Joint Bone Spine 2017;84:59-64.

13. Movahedi M, Costello R, Lunt M, Pye SR, Sergeant JC, Dixon WG. Oral glucocorticoid therapy and all-cause and cause-specific mortality in patients with rheumatoid arthritis: a retrospective cohort study. Eur J Epidemiol 2016;31:1045-55.

14. Widdifield J, Tu K, Carter Thorne J, Bombardier C, Michael Paterson J, Liisa Jaakkimainen R, et al. Patterns of care among patients referred to rheumatologists in Ontario, Canada. Arthritis Care Res 2017;69:104-14.

15. Arthritis Alliance of Canada. [Internet. Accessed August 21, 2017.] Available at: http://arthritisalliance.ca/en/

16. Ahluwalia V, Frank C, Zummer M, Mosher DP. A pan-Canadian approach to inflammatory arthritis models of care. Arthritis Alliance of Canada; 2014. [Internet. Accessed August 21, 2017.] Available from: http://arthritisalliance.ca/images/PDF/eng/ 20140430-2030-IA-MOCFINAL.pdf

17. Barber CE, Marshall DA, Mosher DP, Akhavan P, Tucker L, Houghton K, et al. Development of system-level performance measures for evaluation of models of care for inflammatory arthritis in Canada. J Rheumatol 2016;43:530-40.

18. Radner H, Dixon W, Hyrich K, Askling J. Consistency and utility of data items across European Rheumatoid Arthritis clinical cohorts and registers. Arthritis Care Res 2015;67:1219-29.

19. Jones J, Hunter D. Consensus methods for medical and health services research. BMJ 1995;311:376-80.

20. Dalal S, Khodyakov D, Srinivasan R, Straus S, Adams J. ExpertLens: A system for eliciting opinions from a large pool of non-collocated experts with diverse knowledge. Technol Forecast Soc 2011;78:1426-44.

21. Khodyakov D, Hempel S, Rubenstein L, Shekelle P, Foy R, Salem-Schatz S, et al. Conducting online expert panels: a feasibility and experimental replicability study. BMC Med Res Methodol 2011;11:174.

22. Khodyakov D, Grant S, Barber CE, Marshall DA, Esdaile JM, Lacaille D. Acceptability of an online modified Delphi panel approach for developing health services performance measures: results from 3 panels on arthritis research. J Eval Clin Pract 2017;23:354-60.

23. Fitch K, Bernstein SJ, Aguilar MD, Burnand B, LaCalle JR, Lazaro $\mathrm{P}$, et al. The RAND/UCLA appropriateness method user's manual. Santa Monica, CA: RAND Corporation; 2001. [Internet. Accessed August 21, 2017.] Available from: www.rand.org/pubs/monograph_reports/MR1269.html 
24. Lundon K, Shupak R, Schneider R, Herold McIlroy J. Development and early evaluation of an inter-professional post-licensure education programme for extended practice roles in arthritis care. Physiother Can 2011;63:94-103.

25. Lundon K, Shupak R, Sunstrum-Mann L, Galet D, Schneider R. Leading change in the transformation of arthritis care: development of an inter-professional academic-clinical education training model. Healthc Q 2008;11:62-8.

26. Cooper M, Rouhi A, Barber CE. A systematic review of quality measures for inflammatory arthritis. J Rheumatol, in press.

27. Aletaha D, Neogi T, Silman AJ, Funovits J, Felson DT, Bingham CO 3rd, et al. 2010 rheumatoid arthritis classification criteria: an American College of Rheumatology/European League Against Rheumatism collaborative initiative. Arthritis Rheum 2010; 62:2569-81.

28. Barber CE, Smith A, Esdaile JM, Barnabe C, Martin LO, Faris P, et al. Best practices for cardiovascular disease prevention in rheumatoid arthritis: a systematic review of guideline recommendations and quality indicators. Arthritis Care Res 2015;67:169-79.

29. Barber CE, Marshall DA, Alvarez N, Mancini GB, Lacaille D, Keeling S, et al. Development of cardiovascular quality indicators for rheumatoid arthritis: results from an international expert panel using a novel online process. J Rheumatol 2015;42:1548-55.

30. Singh JA, Saag KG, Bridges SL Jr., Akl EA, Bannuru RR, Sullivan MC, et al. 2015 American College of Rheumatology guideline for the treatment of rheumatoid arthritis. Arthritis Rheumatol 2016;68:1-26.

31. Smolen JS, Landewe R, Breedveld FC, Buch M, Burmester G, Dougados M, et al. EULAR recommendations for the management of rheumatoid arthritis with synthetic and biological disease-modifying antirheumatic drugs: 2013 update. Ann Rheum Dis 2014;73:492-509.

32. Smolen JS, Aletaha D, Bijlsma JW, Breedveld FC, Boumpas D, Burmester G, et al; T2T Expert Committee. Treating rheumatoid arthritis to target: recommendations of an international task force. Ann Rheum Dis 2010;69:631-7.

33. Anderson J, Caplan L, Yazdany J, Robbins ML, Neogi T, Michaud $\mathrm{K}$, et al. Rheumatoid arthritis disease activity measures: American College of Rheumatology recommendations for use in clinical practice. Arthritis Care Res 2012;64:640-7.

34. Loza E, Lajas C, Andreu JL, Balsa A, Gonzalez-Alvaro I, Illera O, et al. Consensus statement on a framework for the management of comorbidity and extra-articular manifestations in rheumatoid arthritis. Rheumatol Int 2015;35:445-58.

35. Roubille C, Richer V, Starnino T, McCourt C, McFarlane A, Fleming P, et al. Evidence-based recommendations for the management of comorbidities in rheumatoid arthritis, psoriasis, and psoriatic arthritis: expert opinion of the Canadian Dermatology-Rheumatology Comorbidity Initiative. J Rheumatol 2015;42:1767-80.

36. Felson DT, Anderson JJ, Boers M, Bombardier C, Chernoff M, Fried B, et al. The American College of Rheumatology preliminary core set of disease activity measures for rheumatoid arthritis clinical trials. The Committee on Outcome Measures in Rheumatoid Arthritis Clinical Trials. Arthritis Rheum 1993;36:729-40.
37. Pincus T, Bergman MJ, Yazici Y. RAPID3-an index of physical function, pain, and global status as "vital signs" to improve care for people with chronic rheumatic diseases. Bull NYU Hosp Jt Dis 2009;67:211-25.

38. Hewlett S, Dures E, Almeida C. Measures of fatigue: Bristol Rheumatoid Arthritis Fatigue Multi-Dimensional Questionnaire (BRAF MDQ), Bristol Rheumatoid Arthritis Fatigue Numerical Rating Scales (BRAF NRS) for severity, effect, and coping, Chalder Fatigue Questionnaire (CFQ), Checklist Individual Strength (CIS20R and CIS8R), Fatigue Severity Scale (FSS), Functional Assessment Chronic Illness Therapy (Fatigue) (FACIT-F), Multi-Dimensional Assessment of Fatigue (MAF), Multi-Dimensional Fatigue Inventory (MFI), Pediatric Quality Of Life (PedsQL) Multi-Dimensional Fatigue Scale, Profile of Fatigue (ProF), Short Form 36 Vitality Subscale (SF-36 VT), and Visual Analog Scales (VAS). Arthritis Care Res 2011;63 Suppl 11: S263-86.

39. Dures EK, Hewlett SE, Cramp FA, Greenwood R, Nicklin JK, Urban M, et al. Reliability and sensitivity to change of the Bristol Rheumatoid Arthritis Fatigue scales. Rheumatology 2013; 52:1832-9.

40. Nicklin J, Cramp F, Kirwan J, Greenwood R, Urban M, Hewlett S. Measuring fatigue in rheumatoid arthritis: a cross-sectional study to evaluate the Bristol Rheumatoid Arthritis Fatigue Multi-Dimensional questionnaire, visual analog scales, and numerical rating scales. Arthritis Care Res 2010;62:1559-68.

41. Nicklin J, Cramp F, Kirwan J, Urban M, Hewlett S. Collaboration with patients in the design of patient-reported outcome measures: capturing the experience of fatigue in rheumatoid arthritis. Arthritis Care Res 2010;62:1552-8

42. Hewlett S. Bristol Rheumatoid Arthritis Fatigue Scales. [Internet. Accessed August 21, 2017.] Available from:

www1.uwe.ac.uk/hls/research/healthandclinicalresearch/researchare as/longtermconditions/fatiguescales.aspx

43. Wolfe F, Michaud K, Pincus T. Development and validation of the health assessment questionnaire II: a revised version of the health assessment questionnaire. Arthritis Rheum 2004;50:3296-305.

44. Bykerk VP, Lie E, Bartlett SJ, Alten R, Boonen A, Christensen R, et al. Establishing a core domain set to measure rheumatoid arthritis flares: report of the OMERACT 11 RA flare Workshop. J Rheumatol 2014;41:799-809.

45. Pincus T, Sokka T. A three-page Standard Protocol to Evaluate Rheumatoid Arthritis (SPERA) for efficient capture of essential data from patients and health professionals in standard clinical care and clinical research. Best Pract Res Clin Rheumatol 2007;21:677-85.

46. Wolfe F, Lassere M, van der Heijde D, Stucki G, Suarez-Almazor M, Pincus T, et al. Preliminary core set of domains and reporting requirements for longitudinal observational studies in rheumatology. J Rheumatol 1999;26:484-9.

47. Askling J, Dixon W. Epidemiology and health services research ongoing initiatives: Task force on requirements for observational treatment registers. [Internet. Accessed August 21, 2017.] Available from: www.eular.org/epidemiology_ongoing_initiatives.cfm

48. Yazdany J, Robbins M, Schmajuk G, Desai S, Lacaille D, Neogi T, et al. Development of the American College of Rheumatology's rheumatoid arthritis electronic clinical quality measures. Arthritis Care Res 2016;68:1579-90. 